\title{
Frugivorous bats prefer information from novel social partners
}

Jip J. C. Ramakers ${ }^{\mathrm{a}, \mathrm{b}, \mathrm{c}}$, Dina K. N. Dechmann ${ }^{\mathrm{c}, \mathrm{d}, \mathrm{e}}$, Rachel A. Page ${ }^{\mathrm{c}}$, and M. Teague O’Mara $^{\text {c,de,e,* }}$

${ }^{\mathrm{a}}$ Department of Biology, Utrecht University, Utrecht, the Netherlands

${ }^{\mathrm{b}}$ Department of Animal Ecology, Netherlands Institute of Ecology (NIOO-KNAW),

Wageningen, the Netherlands

${ }^{\mathrm{c}}$ Smithsonian Tropical Research Institute, Balboa, Ancón, Panama

${ }^{\mathrm{d} D e p a r t m e n t ~ o f ~ M i g r a t i o n ~ a n d ~ I m m u n o-E c o l o g y, ~ M a x ~ P l a n c k ~ I n s t i t u t e ~ f o r ~ O r n i t h o l o g y, ~}$

Radolfzell, Germany

${ }^{\mathrm{e}}$ Department of Biology, University of Konstanz, Konstanz, Germany

fZukunftskolleg, University of Konstanz, Konstanz, Germany

JJCR: jip.ramakers@gmail.com

DKND: ddechmann@orn.mpg.de

RAP: pager@si.edu

MTO: tomara@orn.mpg.de

*Author for correspondence

M. Teague O'Mara

Max Planck Institute of Ornithology

Am Obstberg 1

78315 Radolfzell, Germany

Word count: 5168 
1 Abstract

2

3 Animals use social information from conspecifics as an extended sensor network to monitor their

4 environment and may bias their preference to information from particular individuals, e.g. individuals

5 they are most familiar with. This may be especially important for energy-constrained foragers, such as

6 the frugivorous Peter's tent-making bat Uroderma bilobatum. We used the outcome of a two-

7 demonstrator social learning test in which individual $U$. bilobatum had to make cue-elicited decisions

8 based on food odours from bats from different social groups to test three alternative hypotheses. Bats

9 could show either (i) a preference for information from roostmates ('familiar social partner'), (ii) no

10 bias in information used ('any social partner'), or (iii) a preference for novel cues from non-roostmates

11 ('novel social partner' hypothesis). We found that $U$. bilobatum preferred food demonstrated by nonroostmates to that demonstrated by roostmates, providing support for the novel social partner hypothesis. Uroderma bilobatum bias their attention toward novel conspecifics, perhaps as a strategy for acquiring knowledge of unknown ephemeral food sources, which in turn might help them survive resource bottlenecks.

17 Key words: information centre; information scrounging; roost mate recognition; social information; social learning; Uroderma bilobatum 


\section{Introduction}

Animals use social information from conspecifics to assess the quality of their environment and weight it against their own experiences (Rieucau \& Giraldeau, 2011; Valone \& Templeton, 2002). Various species bias their information use toward individuals with particular qualities, for example, toward older and more prestigious group members (ringtailed lemur; O'Mara \& Hickey, 2012; vervet monkey; van de Waal, Renevey, Favre, \& Bshary, 2010), toward larger individuals (rats: Gerrish \& Alberts, 1995), or toward successful foragers if observable (nine-spined sticklebacks: Coolen, Ward, Hart, \& Laland, 2005). When animals cannot directly observe the foraging success of others, they may have access to other, indirect cues of foraging performance such as food odours on breath or fur or increased urination rates (Danchin, Giraldeau, Valone, \& Wagner, 2004; Valone \& Templeton, 2002). Social roosts have long been hypothesised to function as information centres for information transfer about the availability and location of resources (Ward \& Zahavi, 1973). While this originally required directed behaviour of the individual providing the information, more recent work offers increasing evidence for passive dissemination of indirect information (Bijleveld, Egas, van Gils, \& Piersma, 2010; O'Mara, Dechmann, \& Page, 2014; Ratcliffe \& ter Hofstede, 2005).

Various animal species, including rodents (Galef \& Wigmore, 1983; Valsecchi, Choleris, Moles, Guo, \& Mainardi, 1996) and frugivorous bats (O'Mara et al., 2014; Ratcliffe \& ter Hofstede, 2005), use food odours on the breath of conspecifics to modify food preferences. Although information can be sampled from individuals from the same social group, fission-fusion dynamics may introduce individuals to novel social environments on a regular basis (Aureli et al., 2008). Preference for information from familiar individuals may ensure that individuals have reliable information as they likely forage in the same environment, and familiarity lowers fear or anxiety that inhibits learning (Barta \& Giraldeau, 2001; Beauchamp \& Giraldeau, 1996; Coussi-Korbel \& Fragaszy, 1995; Figueroa, Solà-Oriol, Manteca, \& Pérez, 2013; Laland, 2004). The bulk of evidence for the merits of associating with familiar individuals comes from shoaling fish, which establish social networks where strong associations with particular individuals result in increased foraging opportunities (Atton, Galef, Hoppitt, Webster, \& Laland, 2014; Swaney, Kendal, Capon, Brown, \& Laland, 2000) and increased 
protection from predators through greater shoal cohesion (Chives, Brown, \& Smith, 1995). Pigs, too, learn a food preference from observing a demonstrator from the same pen or litter but not from observing an unknown individual (Figueroa et al., 2013). These examples suggest that social learning from familiar individuals is adaptive when animals forage together in the same environment (CoussiKorbel \& Fragaszy, 1995; Laland, 2004). Rats and gerbils, in contrast, are central place foragers that use the breath of conspecifics to modify food preferences but there is no evidence that information from familiar individuals is more reliable in this scenario (Galef \& Whiskin, 2008).

The decision to use information from familiar versus unfamiliar conspecifics may be particularly important to central place foragers such as Peter's tent-making bat Uroderma bilobatum (Phyllostomidae, Stenodermatinae). Uroderma bilobatum roost in semi-stable social groups and feed primarily on ripe figs (Giannini \& Kalko, 2004; Kalko, Herre, \& Handley, 1996; Sagot \& Stevens, 2012), a resource that is unpredictable in time and space but is shareable among many individuals. Uroderma construct tents as roosts by chewing the secondary veins of palm leaves that then fold over themselves to create a shelter that lasts 10-12 months (Barbour, 1932; Timm, 1987). Roosting groups consist of adult females and their offspring, and may spread among a small number of neighbouring palm tents (Lewis, 1992; Sagot, Rodríguez-Herrera, \& Stevens, 2013). Males appear to seasonally defend tents (Kunz \& McCracken, 1996) but females move freely among multiple tents; yet our longterm mark-recapture data are beginning to show that they are faithful to a limited number of roosts and associated individuals (O’Mara, Faughnan, Dechmann, \& Page, n.d.). This species uses social information from roostmates to make feeding decisions and can, in addition, discriminate the reliability of food-related cues from different roostmates (O'Mara et al., 2014). This offers the opportunity to test three alternative hypotheses concerning the role of social context during the use of inadvertently disseminated information.

First, the bats may preferentially use reliable social cues-i.e., those from familiar social partners - to find their widely distributed but shareable food resources ('familiar social partner' hypothesis). Second, if it is profitable to scrounge information from others due to a high energetic cost of searching for unpredictable food resources (Korine, Kalko, \& Herre, 2000; Morrison, 1978) and a low risk for following social cues, then any social information may always be useful. This may be 
particularly true when animals are confronted with novel food sources and personally acquired information (e.g. about the location or palatability) is outdated, unreliable, or absent (Galef \& Giraldeau, 2001; Kendal, Coolen, van Bergen, \& Laland, 2005; Rieucau \& Giraldeau, 2011). This may promote a strategy to always use social information from any individual that presents it ('any social partner hypothesis') (Kendal et al., 2005; Rendell et al., 2010). A potential disadvantage of always copying is that it may lead to informational cascades (i.e., the erroneous use of information from conspecifics at the expense of the use of personally acquired information) and suboptimal behaviour (Giraldeau, Valone, \& Templeton, 2002; Rieucau \& Giraldeau, 2011). However, animals sampling information within a social roost may be less susceptible to this problem because they likely have access only to honest, time-limited cues that accurately reflect foraging performance (e.g. Bijleveld et al., 2010; Galef, Mason, Preti, \& Bean, 1988; O'Mara et al., 2014). Third, energyconstrained species may benefit from carefully attending to cues available from novel individuals (e.g. immigrants from other social groups), as they might have access to resources currently unknown to the group ('novel social partner' hypothesis). Evidence for this hypothesis from wild, socially living animals is lacking.

We explored these three hypotheses by testing social preference for information in $U$. bilobatum from 'familiar' and 'unfamiliar' individuals. Fig-eating bats can discriminate between species and ripeness of figs by their odour (Korine \& Kalko, 2005). Uroderma bilobatum, in addition, can distinguish whether roostmates have ingested or simply encountered food from the odour on their breath, and they use this information to base their food preference upon (O'Mara et al., 2014). Testing the role of social familiarity in social learning should further enhance our understanding of social group dynamics and how animals may maximise information uptake within information centres.

\section{Methods}

\section{Capture and housing}



different social groups ( $N=5$ roosts; $2-5$ individuals per roost, totalling 25 bats). At our study site in

Gamboa, Panama $\left(9^{\circ} 07^{\prime} \mathrm{N}, 79^{\circ} 42^{\prime} \mathrm{W}\right)$, U. bilobatum roosts under the eaves of overhanging roofs (see Ventocilla, Dillon, \& Smithsonian Tropical Research Institute, 2010 for architectural details). We captured bats from two roosts at a time and paired roosts that were located away from each other and had been observed to have no exchange of individuals in the three years' previous capture events. Bats from each capture were housed in two separate $40 \times 50 \times 50 \mathrm{~cm}$, mesh-lined cages two nights before the start of experiments to acclimate bats to captivity and a diet of banana. Bats were housed at ambient conditions and social groups were visually separated, but olfactory or auditory communication among them may have occurred. All bats were released at their capture site after a maximum of five days.

\section{Experimental procedures}

We tested social preference for information by $U$. bilobatum in a two-demonstrator, two-observer interaction design (Fig. 1). For the experiments, we added 20 drops of one of seven candy flavours (almond, anise, chocolate, coffee, ginger, nutmeg, and sassafras; LorAnn Oils) to $20 \mathrm{~g}$ of $30 \%$ (w/w) sugar solution. Flavoured sugar solution was then added to banana juice (i.e., mashed banana with sugar solution at ratio 3:1). In a previous study, we ensured against any pre-existing bias for the flavours by providing two non-experimental bats with a pairwise choice of flavoured banana and in this way we were able to discard apparently distasteful flavours (i.e., cinnamon, clove, and spearmint; O'Mara et al., 2014).

Experiments took place between 19:00 and 02:00 $\mathrm{h}$ and were video-recorded with a Sony Handycam DCR-SR55 on night-shot mode. For each experiment, a randomly selected observer bat from each of the simultaneously held two social groups was hand-fed $0.5 \mathrm{ml}$ of unflavoured sugar solution to temporarily assuage their hunger, and they were placed into a $50 \times 40 \times 30 \mathrm{~cm}$ mesh-lined interaction arena. A demonstrator bat was then randomly selected from each of the two social groups and they were hand-fed $0.5 \mathrm{ml}$ of two different randomly selected, flavoured sugar solution, followed by $0.5-1.0 \mathrm{ml}$ banana juice with the same flavour; this ensured that bats not only had flavoured sugar 
solution on their breath, but also ingested higher-quality food (O'Mara et al., 2014). The demonstrators

were then placed into the interaction arena where the four bats were allowed to interact for $45 \mathrm{~min}$.

132

133

Bats interacted by sniffing and resting in close proximity from one another. Interactions among individuals could not be quantified as bats moved around between different individuals before taking position and then usually clustered, making identification of individuals difficult. Following this interaction period, each observer was moved to a separate $50 \times 30 \times 30 \mathrm{~cm}$ feeding cage and presented with two dishes containing $15 \mathrm{~g}$ of banana spaced $30 \mathrm{~cm}$ apart on the cage floor, each flavoured with one of the two demonstrated flavours (15 drops of flavoured sugar solution). The observer was allowed to feed for an hour after which food dishes were removed and the total weight of each food eaten quantified to the nearest $0.01 \mathrm{~g}$.

Twenty bats participated in the choice experiment in 14 interaction groups; the remaining five were excluded from the choice test for various reasons such as the lack of completely unfamiliar flavour combinations for a given observer bat, previous exposure to a similar experimental setup, or premature release at capture site due to weight loss (see Ethical note). Each individual bat was tested as observer only once, but several individuals (twelve out of twenty-five captured bats) acted as demonstrators in more than one trial. Five out of twenty observer bats had served as a demonstrator on a previous night and had therefore once come in contact with the non-roostmate demonstrator in reversed roles; in all of these previous encounters these non-roostmates had only eaten unflavoured sugar solution (i.e., bore no flavoured banana on their breath) and were thus not expected to influence the observers' preferences in the subsequent trials when roles were reversed and new information (scented breath) was presented. The setup with four individuals per trials was chosen to minimise time in captivity while performing experiments only during the main natural feeding period of the bats. However, as captured groups differed in size, in eight out of fourteen interactions this led to a situation were no matching observer bat was available; in these cases, we added an equally hungry bat from the other roost that had been tested with different flavours on a previous night, to make sure there were always four bats - two from each roost—interacting under similar conditions. All data have been included as Supplementary Material. 
Experiments were carried out under permit from the Panamanian Autoridad Nacional del Ambiente (ANAM permit SE/AP-12-14) and approval from the Institutional Animal Care and Use Committee at the Smithsonian Tropical Research Institute (2012-0601-2015.). The experiments were designed to minimise time in captivity and we also minimised handling and disturbance. All handling was done by well-trained persons either by or under the supervision of a senior scientist. Feeding protocols and holding conditions were designed based on extensive previous experience. All bats were weighed daily to monitor their health; bats that would not eat and/or lost weight below that at time of capture were excluded from experiments and released at their capture site. As animals were not individually marked externally it was not possible to observe them after their release, but high recapture rates from animals used in these and previous experiments show no detrimental health effects such as weight loss.

Data analysis

Analysis was done in R 3.2.0 (R Core Team, 2015). To initially rule out potential non-independence of having two observer bats simultaneously in the interaction arena, we estimated the variance in preferential first approaches (see below) induced by 'interaction ID' (i.e., an index that links observers that were simultaneously in the interaction arena) as a random effect in an intercept-only mixed-effects model with binomial errors. We found no variance in food choices explained by the individual trial numbers (variance: $0 \pm 0 \mathrm{SD}$ ) and we then accepted that each observation was independent. Additionally, to assess bias for demonstrators with a larger body mass (Gerrish \& Alberts, 1995), we compared body mass (g) of the two demonstrators using a linear mixed-effects model with observer nested within demonstrator pair as a random effect, and found no statistically significant difference $\left(F_{1,19}=0.12, P=0.73\right)$. Combined, these results suggested that there were likely no factors other than demonstrators' group membership that influenced the observers' food preference. 
generally approached and sniffed both dishes several times before making a decision and we consider here only the approach that led to the first bite. We also calculated a Bayes factor (i.e., the odds of the alternative over the null hypothesis) for the binomial probability tests using the BayesFactor package (Morey, Rouder, \& Jamil, 2015) to additionally report an informative evidence ratio (Johnson, 2013).

Second, for each observer bat we obtained the proportion of the total amount of food eaten from either food type. This dataset was skewed toward either $100 \%$ or $0 \%$, and violates the assumption of tests that are commonly used in choice studies with similar percent data such as Wilcoxon signed-rank tests (e.g. O'Mara et al., 2014; Ratcliffe \& ter Hofstede, 2005), Mann-Whitney $U$ tests (e.g. Galef \& Wigmore, 1983), or even $t$-tests (e.g. Coolen et al., 2005). Therefore, we used Bayesian nonparametric bootstrapping ( $N=1000$ samples) to estimate $95 \%$ credibility intervals around the medians of the proportions (see Bååth, 2015 for the R source code). This procedure is similar to standard nonparametric bootstrapping and uses resampling with replacement to calculate a posterior median for each of $N$ drawn weights from a uniform Dirichlet distribution (Rubin, 1981). The Dirichlet distribution is the multivariate generalisation of the beta distribution, where all proportions are normalised to range between and add up to 1 (Frigyik, Kapila, \& Gupta, 2010). This makes it a suitable prior for estimating posterior medians for our proportional dataset.

\section{Results}

Observer $U$. bilobatum preferentially first approached and ate food demonstrated by non-roostmates in 15 out of 20 trials (binomial test: $P=0.041$ ). This is reinforced by the Bayes factor of 3.5 , which indicates modest evidence against the null hypothesis of equal distribution of first approaches (Kass \& Raftery, 1995). Bats consumed a total of $2.7 \pm 2.2 \mathrm{~g}$ (mean $\pm \mathrm{SD}$ ) of flavoured banana and ate more food demonstrated by non-roostmates (median proportion: $0.90 ; 95 \%$ credibility interval: $0.65-1.00$ ) than food demonstrated by roostmates (median proportion: $0.10 ; 95 \%$ credibility interval: $0.00-0.35$; Fig. 2).

Although in a previous study (O'Mara et al., 2014) U. bilobatum readily consumed all of the seven flavours presented to them, bats in our study consistently ate the least from nutmeg-flavoured banana 
in the five trials in which it was presented, regardless of demonstrator familiarity, suggesting that nutmeg was a less preferable flavour than the other ones. Therefore, we reran the analysis on a restricted dataset without nutmeg trials $(N=15)$ and found that this conservative analysis produced similar results for preferential first approaches ( 12 out of 15 ; binomial test: $P=0.035$; Bayes factor: 4.1) and for the median proportions eaten $(0.90$ and $0.10 ; 95 \%$ credibility intervals: $0.73-1.00$ and $0.00-0.27$, respectively), but partly removed the bimodality of the response (Fig. A1).

\section{Discussion}

We tested whether Uroderma bilobatum prefer social information from familiar versus unfamiliar conspecifics. Our results show that not only do they discriminate group membership, but also that they are more attracted to social information from outside of their roosting group.

Familiarity can have strong effects on decision making. Various animals tend to learn more quickly from familiar demonstrators (Atton et al., 2014; Figueroa et al., 2013; Swaney et al., 2000; Valsecchi et al., 1996). However, rats have been shown to slightly prefer information from novel individuals (Galef \& Whiskin, 2008), which may be a result of observers spending more time sniffing and in close proximity to unfamiliar individuals. While $U$. bilobatum show the same preference for unfamiliar demonstrators as rats, it is unclear if this is a result of proximity, as we often could not determine which bat interacted most with whom because all four typically rested in a single group in contact with one another. This clustering, however, likely enabled bats to sample all individuals repeatedly. Novelty, like in rats but in contrast to fish and pigs, appears to stimulate interest with respect to social information in $U$. bilobatum.

This interest in novel individuals may be a strategy to exploit others as an extended sensor network to monitor the environment (Galef \& Giraldeau, 2001; King \& Cowlishaw, 2007; Valone \& Templeton, 2002). In this way, information transfer through social learning can reduce the cost of monitoring resources that are widely dispersed and unpredictable, such as figs. Uroderma bilobatum do use information from roostmates to establish food preferences (O'Mara et al., 2014). However, 
when different sources of information are present, the most novel one (i.e., from non-roostmates) might be considered most valuable as this allows the observer to establish a broader sample of what is available beyond what is known to the group. This differs, for example, from the preferences for familiar demonstrators in shoaling fish (Atton et al., 2014; Swaney et al., 2000), where close association among individuals results in following each other to food. The high cost of search flights executed by fig-eating bats (Morrison, 1978) may select for social strategies that allow for efficient information sampling at the roost (O'Mara et al., 2014). Furthermore, the fission-fusion social communities of $U$. bilobatum facilitate the exchange of individuals among core roosting areas (Sagot \& Stevens, 2012). The occasional introduction of new individuals, or at least animals that have not been recently encountered, offers group members more diverse information sources that are less likely to be correlated with one another (Torney, Lorenzi, Couzin, \& Levin, 2015). The preference for information from non-roostmates may consequently be a way to increase decision accuracy by integrating a collective decision-making approach when switching to new resources, but further work is needed to test how a quorum-based decision-making process (Conradt \& Roper, 2005) can occur in bats.

It is still unknown whether social learning within roosts leads to increased foraging efficiency, but frugivorous bats modify their food preferences based on social information in a variety of contexts (O'Mara et al., 2014; Ratcliffe \& ter Hofstede, 2005) and in U. bilobatum learned food preference in captivity does translate to effective information transfer in the wild (O'Mara et al., 2014). While the crown of a fig tree is a dense and shareable food resource, a single crop of ripe figs only lasts for two to three days, and trees can be widely dispersed throughout the landscape and therefore fruit ripening events are difficult to predict in time and space (Korine et al., 2000). The ability to discriminate cue quality (O'Mara et al., 2014) and the flexibility to use social information from roostmates as well as expanding the repertoire by using information from new social partners during resource bottlenecks may be important in the stability of social groups within an information centre (Beauchamp \& Giraldeau, 1996; Lachmann, Sell, \& Jablonka, 2000; Rendell et al., 2010), particularly if the cues associated with the resources are reliable. 
272 This study was supported in part by an Erasmus student fellowship to JJCR; additional funding was

273 provided by the University of Konstanz, the Max Planck Institute for Ornithology, and the

274 Smithsonian Tropical Research Institute. We are grateful to researchers in the STRI bat lab for their 275 logistic support, in particular Jenna Kohles, Sebastian Stockmaier, and Tom Faughnan. Three 276 anonymous reviewers kindly provided constructive comments on a previous version of the manuscript. 


\section{References}

Atton, N., Galef, B. J., Hoppitt, W., Webster, M. M., \& Laland, K. N. (2014). Familiarity affects social network structure and discovery of prey patch locations in foraging stickleback shoals. Proceedings of the Royal Society B, 281, 20140579.

Aureli, F., Schaffner, C. M., Boesch, C., Bearder, S. K., Call, J., Chapman, C. A., et al. (2008). Fission-fusion dynamics. Current Anthropology, 49, 627-654.

Bååth,

R.

(2015).

Easy

Bayesian

bootstrap

in

$\mathrm{R}$. [https://gist.github.com/rasmusab/11a683a441a4147b4675].

Barbour, T. (1932). A peculiar roosting habit of bats. The Quarterly Review of Biology, 7, 307-312.

Barta, Z., \& Giraldeau, L.-A. (2001). Breeding colonies as information centers: a reappraisal of information-based hypotheses using the producer-scrounger game. Behavioral Ecology, 12, $121-127$.

Beauchamp, G., \& Giraldeau, L.-A. (1996). Group foraging revisited: information sharing or producer-scrounger game? American Naturalist, 148, 738-743.

Bijleveld, A. I., Egas, M., van Gils, J. A., \& Piersma, T. (2010). Beyond the information centre hypothesis: communal roosting for information on food, predators, travel companions and mates? Oikos, 119, 277-285.

Chives, D. P., Brown, G. E., \& Smith, R. J. F. (1995). Familiarity and shoal cohesion in fathead minnows (Pimephales promelas): implications for antipredator behaviour. Canadian Journal of Zoology, 73, 955-960.

Conradt, L., \& Roper, T. J. (2005). Consensus decision making in animals. Trends in Ecology \& Evolution, 20, 449-456.

Coolen, I., Ward, A. J. W., Hart, P. J. B., \& Laland, K. N. (2005). Foraging nine-spined sticklebacks prefer to rely on public information over simpler social cues. Behavioral Ecology, 16, 865870.

Coussi-Korbel, S., \& Fragaszy, D. M. (1995). On the relation between social dynamics and social learning. Animal Behaviour, 50, 1441-1453. 
Danchin, E., Giraldeau, L.-A., Valone, T. J., \& Wagner, R. H. (2004). Public information: from nosy neighbors to cultural evolution. Science, 305, 487-491.

Figueroa, J., Solà-Oriol, D., Manteca, X., \& Pérez, J. F. (2013). Social learning of feeding behaviour in pigs: effects of neophobia and familiarity with the demonstrator conspecific. Applied Animal Behaviour Science, 148, 120-127.

Frigyik, B. A., Kapila, A., \& Gupta, M. (2010). Introduction to the Dirichlet distribution and related processes: University of Washington Electrical Engineering, technical report UWEETR-20100006.

Galef, B. G., Mason, J. R., Preti, G., \& Bean, N. J. (1988). Carbon sulfide: a semiochemical mediating socially-induced diet choice in rats. Physiology \& Behavior, 42, 119-124.

Galef, B. G., \& Whiskin, E. E. (2008). Effectiveness of familiar kin and unfamiliar nonkin demonstrator rats in altering food choices of their observers. Animal Behaviour, 76, 13811388.

Galef, B. G. J., \& Giraldeau, L.-A. (2001). Social influences on foraging in vertebrates: causal mechanisms and adaptive functions. Animal Behaviour, 61, 3-15.

Galef, B. G. J., \& Wigmore, S. W. (1983). Transfer of information concerning distant foods: a laboratory investigation of the 'information-centre' hypothesis. Animal Behaviour, 31, 748758.

Gerrish, C. J., \& Alberts, J. R. (1995). Differential influence of adult and juvenile conspecifics on feeding by weanling rats (Rattus norvegicus): a size-related explanation. Journal of Comparative Psychology, 109, 61-67.

Giannini, N. P., \& Kalko, E. K. V. ( 2004). Trophic structure in a large assemblage of phyllostomid bats in Panama. Oikos, 105, 209-220.

Giraldeau, L.-A., Valone, T. J., \& Templeton, J. J. (2002). Potential disadvantages of using socially acquired information. Philosophical Transactions of the Royal Society of London B, 15591566.

Johnson, V. E. (2013). Revised standards for statistical evidence. Proceedings of the National Academy of Sciences of the United States of America, 110, 19313-19317. 
Kalko, E. K. V., Herre, E. A., \& Handley, C. O., Jr. (1996). Relation of fig fruit characteristics to fruiteating bats in the New and Old World tropics. Journal of Biogeography, 23, 565-576.

Kass, R. E., \& Raftery, A. E. (1995). Bayes Factors. Journal of the American Statistical Association, 90, 773-795.

Kendal, R. L., Coolen, I., van Bergen, Y., \& Laland, K. N. (2005). Trade-offs in the adaptive use of social and asocial learning. Advances in the Study of Behavior, 35, 333-379.

King, A. J., \& Cowlishaw, G. (2007). When to use social information: the advantage of large group size in individual decision making. Biology Letters, 3, 137-139.

Korine, C., \& Kalko, E. K. V. (2005). Fruit detection and discrimination by small fruit-eating bats (Phyllostomidae): echolocation call design and olfaction. Behavioral Ecology and Sociobiology, 59, 12-23.

Korine, C., Kalko, E. K. V., \& Herre, E. A. (2000). Fruit characteristics and factors affecting fruit removal in a Panamanian community of strangler figs. Oecologia, 123, 560-568.

Kunz, T. H., \& McCracken, G. F. (1996). Tents and harems: apparent defence of foliage roosts by tent-making bats Journal of Tropical Ecology, 12, 121-137.

Lachmann, M., Sell, G., \& Jablonka, E. (2000). On the advantage of information sharing. Proceedings of the Royal Society B, 267, 1287-1293.

Laland, K. N. (2004). Social learning strategies. Learning \& Behavior, 32, 4-14.

Lewis, S. E. (1992). Behavior of Peter's tent-making bat, Uroderma bilobatum, at maternity roosts in Costa Rica. Journal of Mammalogy, 73, 541-546.

Morey, R. D., Rouder, J. N., \& Jamil, T. (2015). Package 'BayesFactor': Computation of Bayes Factors for Common Designs. The Comprehensive R Archive Network.

Morrison, D. W. (1978). Foraging ecology and energetics of the frugivorous bat Artibeus jamaicensis. Ecology, 59, 716-723.

O'Mara, M. T., Faughnan, T., Dechmann, D. K. N., \& Page, R. A. (n.d.). Resource availability and roosting networks in tent-making bats. Manuscript in preparation.

O'Mara, M. T., Dechmann, D. K. N., \& Page, R. A. (2014). Frugivorous bats evaluate the quality of social information when choosing novel foods. Behavioral Ecology, 25, 1233-1239. 
O'Mara, M. T., \& Hickey, C. M. (2012). Social influences on the development of ringtailed lemur feeding ecology. Animal Behaviour, 84, 1547-1555.

R Core Team. (2015). R: A language and environment for statistical computing. Vienna, Austria: R Foundation for Statistical Computing. [https://cran.r-project.org/].

Ratcliffe, J. M., \& ter Hofstede, H. M. (2005). Roosts as information centres: social learning of food preferences in bats. Biology Letters, 1, 72-74.

Rendell, L., Boyd, R., Cownden, D., Enquist, M., Eriksson, K., Feldman, M. W., \& Laland, K. N. (2010). Why copy others? Insights from the social learning strategies tournament. Science, $328,208-213$.

Rieucau, G., \& Giraldeau, L.-A. (2011). Exploring the costs and benefits of social information use: an appraisal of current experimental evidence. Philosophical Transactions of the Royal Society of London B, 366, 949-957.

Rubin, D. B. (1981). The Bayesian Bootstrap. Annals of Statistics, 9, 130-134.

Sagot, M., Rodríguez-Herrera, B., \& Stevens, R. D. (2013). Macro and microhabitat associations of the Peter's tent-roosting bat (Uroderma bilobatum): human-induced selection and colonization? Biotropica, 45, 511-519.

Sagot, M., \& Stevens, R. (2012). The evolution of group stability and roost lifespan: perspectives from tent-roosting bats. Biotropica, 44, 90-97.

Swaney, W., Kendal, J., Capon, H., Brown, C., \& Laland, K. N. (2000). Familiarity facilitates social learning of foraging behaviour in the guppy. Animal Behaviour, 62, 591-598.

Timm, R. M. (1987). Tent construction by bats of the genera Artibeus and Uroderma. In B. D. Patterson \& R. M. Timm (Eds.), Fieldiana: Zoology (n. s.) (pp. 188-212).

Torney, C. J., Lorenzi, T., Couzin, I. D., \& Levin, S. A. (2015). Social information use and the evolution of unresponsiveness in collective systems. Journal of the Royal Society Interface, 12, 20140893.

Valone, T. J., \& Templeton, J. J. (2002). Public information for the assessment of quality: a widespread social phenomenon. Philosophical Transactions of the Royal Society of London B, $357,1549-1557$. 
389 Valsecchi, P., Choleris, E., Moles, A., Guo, C., \& Mainardi, M. (1996). Kinship and familiarity as factors affecting social transfer of food preferences in adult Mongolian gerbils (Meriones unguiculatus). Journal of Comparative Psychology, 110, 243-251.

392

van de Waal, E., Renevey, N., Favre, C., \& Bshary, R. (2010). Selective attention to philopatric models causes directed social learning in wild vervet monkeys. Proceedings of the Royal Society B, 277, 2105-2111.

Ventocilla, J., Dillon, K., \& Smithsonian Tropical Research Institute. (2010). Gamboa: a guide to its natural and cultural heritage: Panama: Smithsonian Tropical Research Institute. centres" for food-finding. Ibis, 115, 517-534. 
Figure 1. Schematic of the experimental design. Demonstrator Uroderma bilobatum (blue and orange

400 shading) from each social group were hand-fed banana juice with a randomly selected flavour (a) and

401 subsequently placed into an interaction arena with a randomly selected observer bat from each roost

402 (b). Observer bats were then (c) offered a choice between two dishes of banana with the two

403 demonstrated flavours. Arrows denote the observer bats' pathways; food colours correspond to their

404 demonstrators.

405

406 Figure 2. Proportion of total food eaten by observer Uroderma bilobatum from each demonstrated

407 food type. Overlapping points are values for individual bats $(N=20)$, with each point mirrored at

408 the other side of the graph; black horizontal lines denote the posterior medians resulting from

409 bootstrapping, with $95 \%$ credibility intervals in red. The dotted horizontal line indicates the 0.5 line

410 of no preference.

411

412 Figure A1. Proportion of total food eaten by observer Uroderma bilobatum from each demonstrated

413 food type based on the dataset excluding trials with nutmeg as one of the presented flavours.

414 Overlapping points are values for individual bats $(N=15)$, with each point mirrored at the other side

415 of the graph; black horizontal lines denote the posterior medians resulting from bootstrapping, with $95 \%$ credibility intervals in red. The dotted horizontal line indicates the 0.5 line of no preference. 
This study was supported in part by an Erasmus student fellowship to JJCR; additional funding was provided by the University of Konstanz, the Max Planck Institute for Ornithology, and the Smithsonian Tropical Research Institute. We are grateful to researchers in the STRI bat lab for their logistic support, in particular Jenna Kohles, Sebastian Stockmaier, and Tom Faughnan. Three anonymous reviewers kindly provided constructive comments on a previous version of the manuscript. 


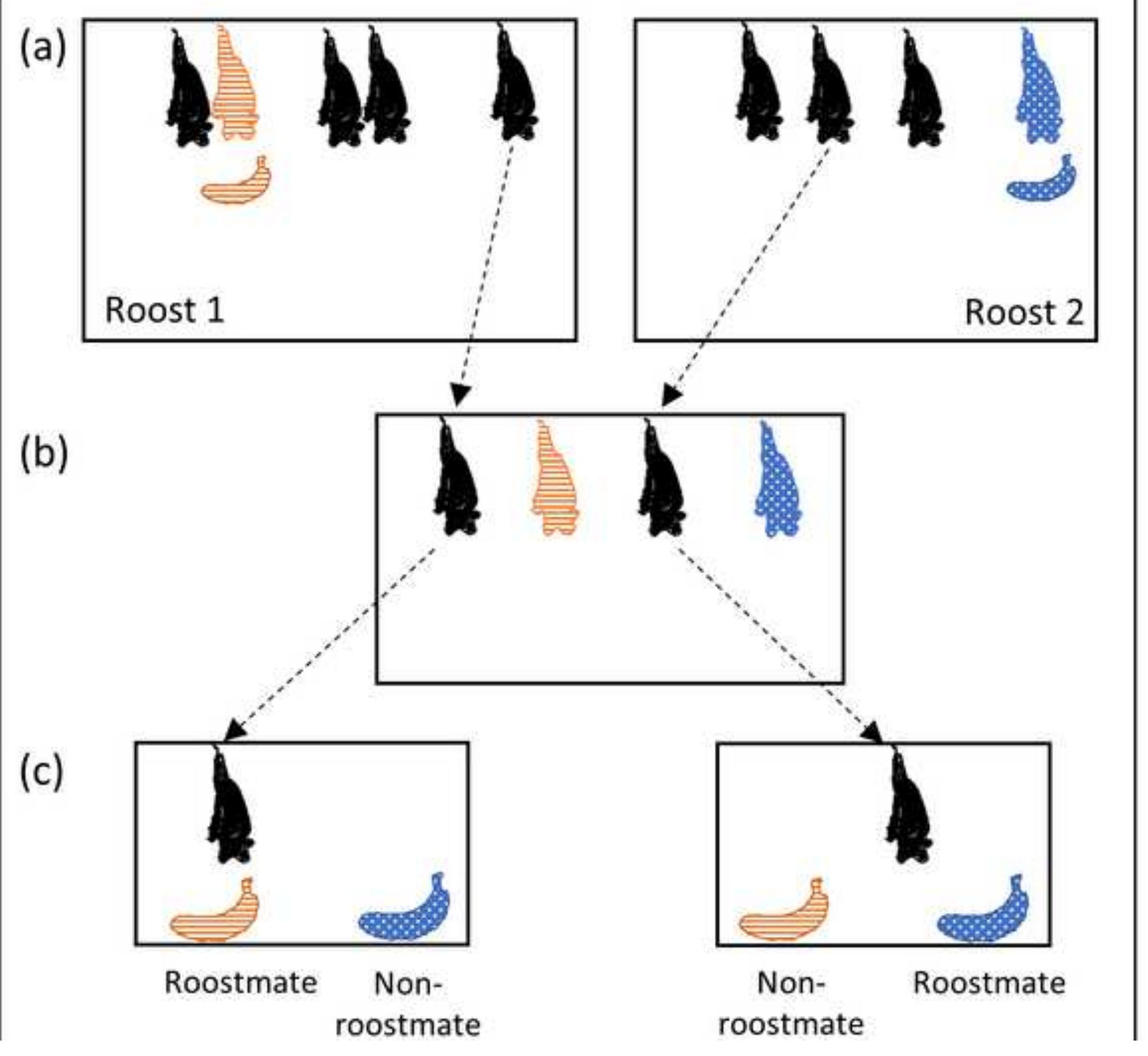




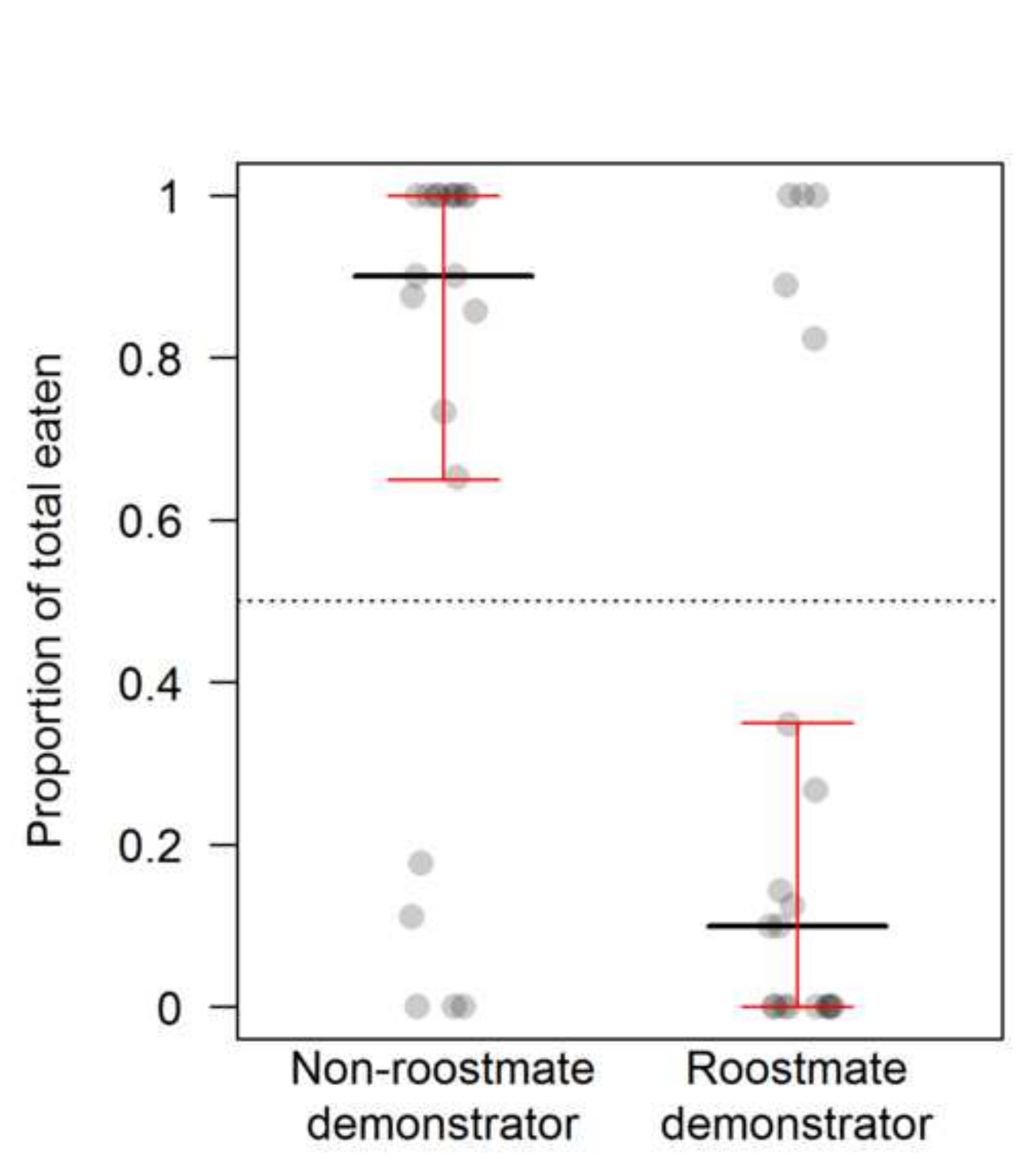

Figure 2
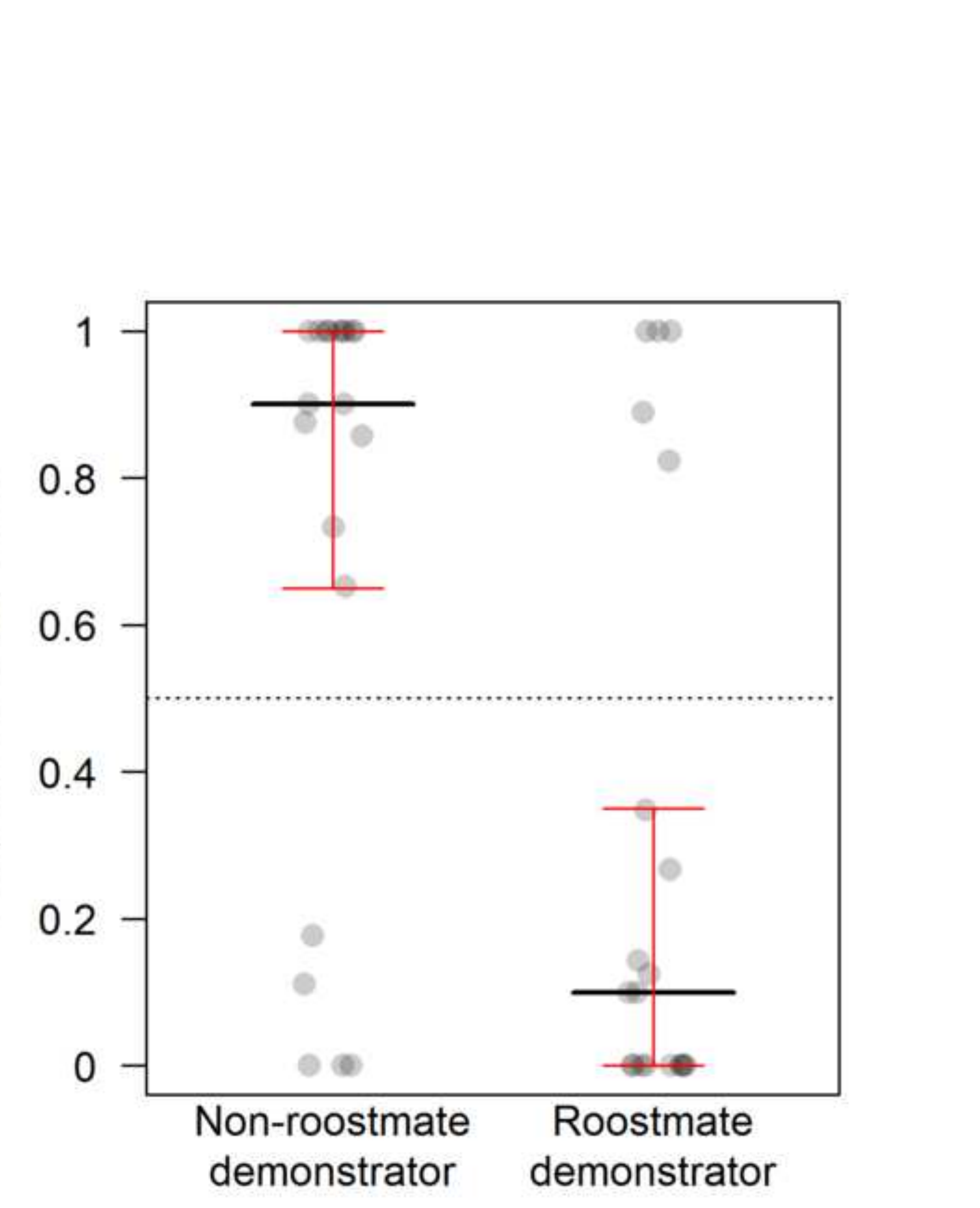


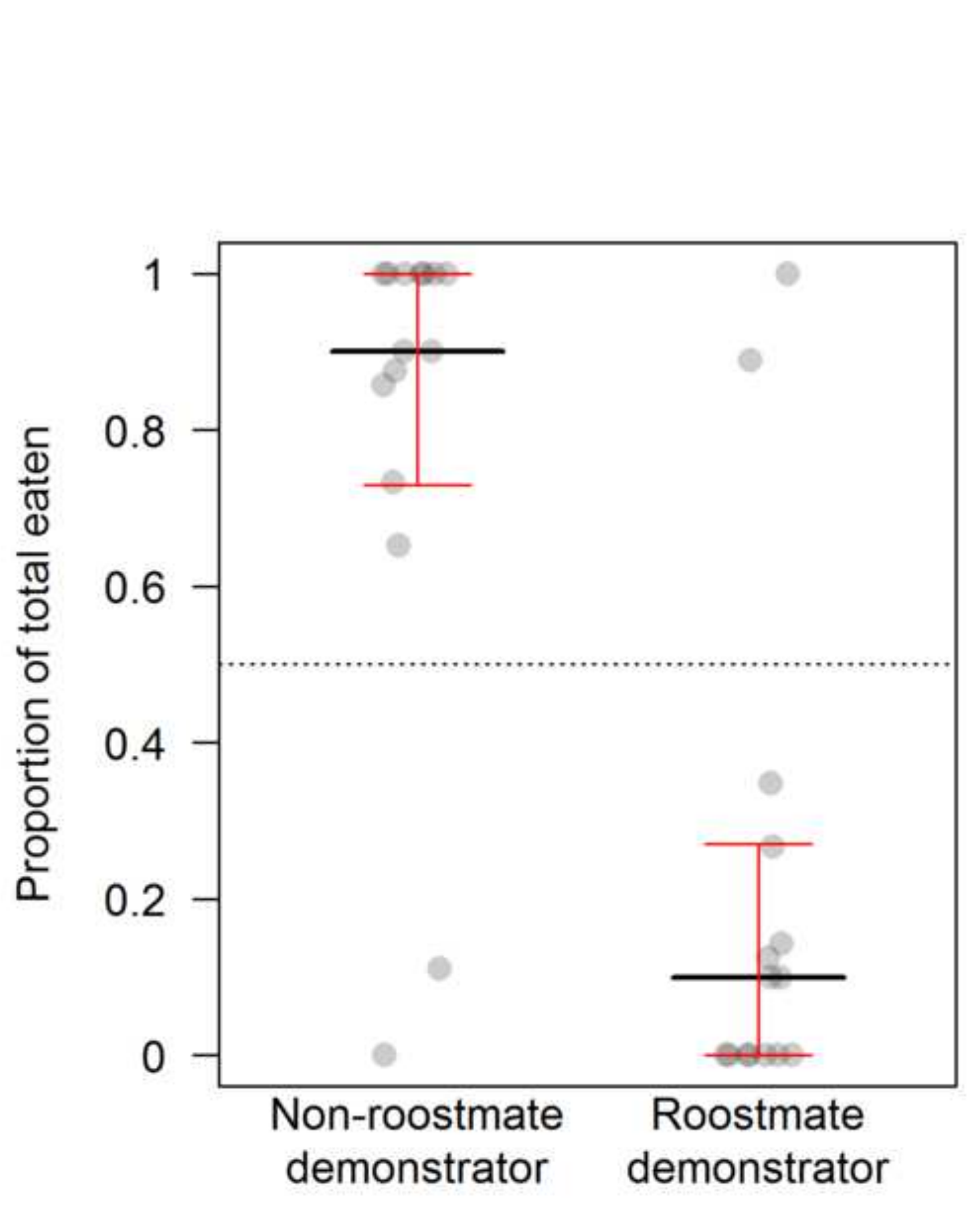

FigureA1

(

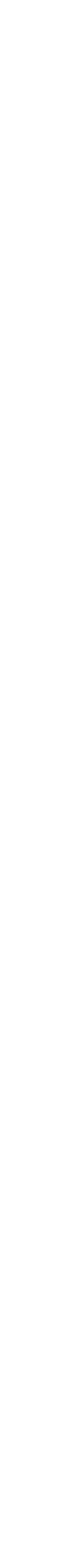

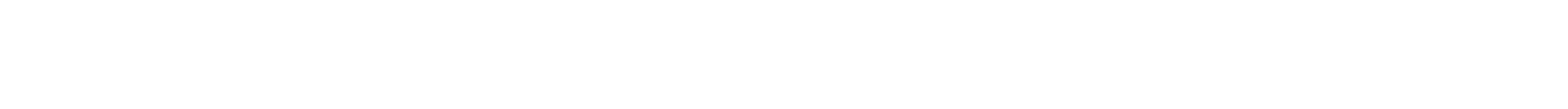

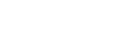

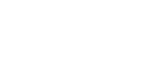
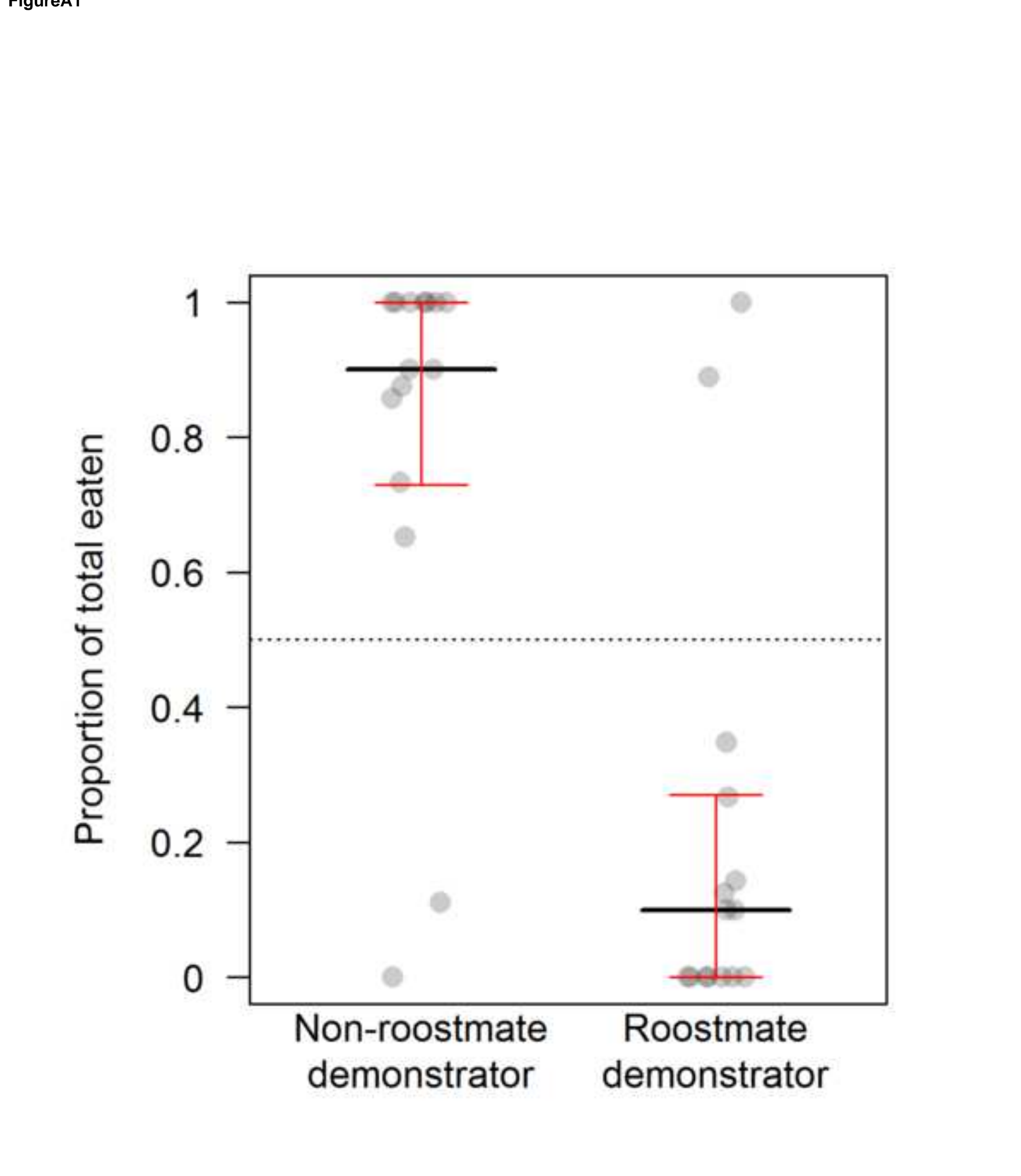